\title{
Transformação das Forças Armadas da Colômbia no pós-conflito armado: mudanças no emprego doméstico e na atuação internacional
}

\author{
Colombian Armed Forces tran sformation in the post-armed conflict: changes in the domestic employment \\ and the international actuation
}

DOI: https://doi.org/10.22456/2178-8839.108254

João Estevam dos Santos Filho Programa de Pós-Graduação em Relações Internacionais San Tiago Dantas (UNESP, UNICAMP, PUC-SP), São Paulo, Brasil joaoestevam08@gmail.com $\mathbf{C}$

Alexander Arciniegas Carreño Facultad de Ciencias Políticas y Gobierno da Universidad Pontificia Bolivariana (UPB), Bucaramanga, Colômbia arciniegascol@hotmail.com

\section{Resumo}

Com o enfraquecimento estratégico das guerrilhas e o início dos diálogos de paz entre as FARC e o governo nacional, iniciou-se uma situação de pósconflito armado, que tem sido acompanhada de uma transformação das Forças Armadas colombianas. O presente artigo se propõe a analisar esse processo iniciado em 2011 com o objetivo de identificar o novo papel que lhes tem sido delegado no contexto de pós - conflito que começou a assinatur a dos Acordos de Paz de Havana em 2016. Trabalha-se com a hipótese de que esse processo tem, por um lado, consolidado as Forças Militares colombian as como instituição voltada para o cumprimento de tarefas subsidiárias e, por outro, contribuído para uma renovação da dependência militar em relação aos Estados Unidos, ainda que sobre bases diferentes daquelas observadas durante a vigência do Plano Colômbia. A metodologia utilizada consistiu em análise de dados coletados em bases internacionais, análise de documentos do governo colombiano e revisão de literatura sobre transformação militar. Conquanto esse processo envolva as três Forças Armadas (Exército, Marinha e Força Aérea), a primeira tem sido a mais impactada e, portanto, um maior foco da análise recairá sobre ela.

Palavras-chave: Transformação militar; Colômbia; Pós-Conflito;

\begin{abstract}
With the guerrilla's strategic weakening and the establishment of the peace dialogues between the FARC and the national government, it started a situation of post-armed conflict, which has been accompanied with the transformation of the Colombian armed forces. In this way, the present paper aims to analyze this initiated in 2011, with the objective of identifying the new role that has been delegated to the military in the context of post-conflict that started with the signing of the Havana Peace Accords in 2016. The hypothesis of the paper is that the process, in one hand, has been consolidating the Colombian armed forces as an institution turned to the accomplishment of subsidiary tasks and, in the other, it has contributed to a renewal of the military dependency with the USA, although with different bases in relation to those observed during the Plan Colombia time. The methodology employed in this research consisted of data analysis collected in international databases, analysis of documents from the Colombian government and literature review about military transformation. Despite this process involving the three armed forces (Army, Navy and Air Force), the first one has been more affected, which for this reason it will be more analyzed.
\end{abstract}

Keywords: Military Transformation; Colombia; Post-Conflict; 


\section{Introdução}

Após mais de meio século de conflito armado, em 2016, o governo colombiano chegou a um acordo de paz com as Forças Armadas Revolucionária da Colômbia (FARC), começando um contexto de pós -conflito. Assim, as Forças Armadas da Colômbia tiveram que iniciar um processo de transformação militar que incluiria tanto uma renovação doutrinária, quanto uma mudança no emprego de seus efetivos. Conquanto seja um evento recente, iniciado em 2011, já mostra importantes resultados e define com clareza as tendências das instituições militares colombianas.

Nesse sentido, este artigo se propõe a analisar o processo de transformação militar por que tem passado as Forças Armadas colombianas a fim de identificar o novo papel que lhes tem sido delegado na situação de pós -conflito. Trabalhase com a hipótese de que esse processo tem, por um lado, consolidado as Forças Militares colombianas como instituições voltadas para o cumprimento de tarefas subsidiárias e, por outro, contribuído para uma renovação da dependência militar em relação aos Estados Unidos (EUA), ainda que sobre bases diferentes daquelas observadas durante a vigência do Plano Colômbia.

Para a realização deste trabalho foram utilizados os seguintes métodos de pesquisa: revisão bibliográfica sobre transformação militar e papel das Forças Armadas na América Latina e da Colômbia. Foram analisados dados coletados em bases internacionais como a Base de Dados sobre Transferência de Armamentos e de Gasto Militar do Stockholm International Peace Research Institute (SIPRI) e o The Military Balance do International Institute for Strategic Studies (IISS), assim como em relatórios de entidades públicas e privadas da Colômbia e dos EUA. Por fim, foram realizadas análises de documentos do Ministério da Defesa da Colômbia. O escopo temporal da pesquisa abrange o período de 2011 a 2019.

Para realizar essa análise, o período foi dividido em duas fases:2011 a 2016 (fim do perfil contrainsurgente) e 2017 a 2019 (consolidação do perfil multimissão). Tendo como sabe essa divisão, será realizada uma análise discursiva dos principais documentos de defesa desse período, dos aspectos quantitativos (orçamento militar, variação do número de efetivos e aquisição de equipamentos), das mudanças organizacionais, das inovações doutrinárias, do tipo de emprego das Forças Armadas e de sua relação com o ambiente internacional (outros países e instituições externas).

Além desta introdução, o artigo contém mais quatro seções. Na próxima, é realizada uma discussão teórica sobre o conceito de transformação militar, tanto nos países desenvolvidos, quanto na América Latina, observando também os papéis das Forças Armadas dos países da região no pós-Guerra Fria e o papel dos EUA nesse processo. O objetivo dessa seção é identificar um conceito de transformação militar que auxilie na análise do caso colombiano. A terceira seção traz uma breve descrição da transformação ocorrida entre 1998 e 2010, a fim de identificar o ponto de partida para o processo atual. Na quarta, éfeita uma descrição da transformação para o pós -conflito, considerando o conceito de força multimissão como o principal aspecto desse processo. Por fim, são feitas algumas considerações finais sobre os resultados obtidos ao longo da pesquisa.

\section{Transformação militar no pós-Guerra Fria}

O debate teórico sobre o conceito de transformação militar na literatura de Ciência Política e Relações Internacionais ganhou maior relevância a partir do período pós-Guerra Fria, sobretudo na década de 2000, quando se passou a analisar os processos iniciados nas Forças Armadas dos países desenvolvidos, sobretudo dos membros da Organização do Tratado do Atlântico Norte (OTAN). As mudanças internas e externas que se seguiramà desintegração do bloco soviético na década de 1990 geraram a necessidade de adaptar as instituições militares para novos cenários de emprego. A emergência de novos tipos de guerras a partir de crises dos Estados periféricos nas décadas de 1990, definidos pela separação mais difusa entre civis e militares, enfrentamentos menos diretos e com fontes de financiamento ilegais, também requereu mudanças nas Forças Armadas dos países desenvolvidos (KALDOR, 2012). 
Em seu trabalho sobre transformação militar nos países da OTAN e, principalmente, nos EUA, Sloan (2008) afirma que esse processo é resultado tanto do novo contexto de segurança internacional no pós -Guerra Fria quanto das mudanças tecnológicas promovidas pelo complexo industrial-militar norte-americano em conjunto com o Estado, sobretudo a partir da década de 1980. Essas inovações tecnológicas teriam resultado no que foi denominado "Revolução nos Assuntos Militares" (RMA, na sigla em inglês). Por sua vez, a autora define transformação militar como sendo um processo de aumentos descontínuos nas capacidades das Forças Armadas de um país para desempenhar novas funções sob novos parâmetros de atuação. Nesse sentido, envolveria três dimensões: tecnológica, doutrinária e organizacional.

A primeira estaria relacionada aos novos desenvolvimentos tecnológicos na área de defesa - sobretudo aqueles relacionados aos avanços na área de tecnologia da informação - que, iniciados principalmente nos EUA, propagaram-se para os demais países da OTAN. Por sua vez, a dimensão doutrinária teria como principais características: transição de exércitos de massa e pesados para maisleves e com possibilidade de serem empregados em missões expedicionárias; maior mobilidade no teatro de operações, a fim de agir de modo mais disperso, movimentando-se rapidamente e enfrentando situações instáveis e maior ênfase nas operações conjuntas. Por fim, a dimensão organizacional incluiria unidades menores, com efetivos mais qualificados, abandono do sistema de conscritos e maior utilização de militares profissionais (SLOAN, 2008).

Outros autores corroboram as ideias de Sloan (2008), ainda que ressaltando outros aspectos, comoé o caso das análises de Manigart (2006) e de Dandeker (2006) sobre a construção de Forças Armadas mais flexíveis, de caráter mais "constabular", voltadas para o emprego em missões internacionais, sobretudo na periferia do sistema internacional. Também Terriff e Farrell (2001) apoiam essa concepção, afirmando que as mudanças militares no Ocidente envolveriam um maior foco em atuação nas crises dos países subdesenvolvidos e no desenvolvimento de tecnologias mais sofisticadas. Por sua vez, Moskos, Segal e Williams (2000) identificam um novo perfil de força dos países desenvolvidos do Ocidente, que eles denominam "Forças Armadas pós-modernas", caracterizadas por maior interpenetrabilidade entre as esferas civil e militar; maior foco em missões não militares no sentido tradicional; utilização das Forças Armadas em missões internacionais comandadas por entidades supranacionais e internacionalização dessasinstituições militares.

Apesar do avanço teórico na definição de transformação militar nos países desenvolvidos, na América Latina, esse tema ainda não alcançou o mesmo grau de significância no período pós-Guerra Fria. Nesse sentido, os trabalhos de Villamizar (2003), Covarrubias (2004) e Alda Mejías (2019) têm buscado avançar na discussão. Os três corroboram a definição dada por Sloan (2008), ou seja, de que a transformação das Forças Armadas seria um processo caracterizado por mudanças de ordem doutrinária, organizacional e tecnológica, gerando novas capacidades a fim de desempenhar novas missões e, desse modo, adquirir novos papéis. Assim, neste trabalho, o conceito de transformação militar corresponde a essa definição.

Com essas mudanças, desde o final da Guerra Fria e com a volta dos regimes democráticos na região, as Forças Armadas dos países latino-americanos têm desempenhado um papel mais voltado para a garantia da estabilização doméstica. Hunter (1996) identifica cinco principais missões nas quais os militares seriam empre gados: defesa convencional, voltada para a manutenção da integridade territorial; manutenção da paz internacional; segurançainterna, incluindo contrainsurgência e combate ao narcotráfico; ação cívica e funções de desenvolvimento socioeconômico. De semelhante modo, Pion-Berlin (2016) identifica quatro missões das Forças Armadas latino-americanas no período democrático: defesa convencional, segurança interna (sobretudo voltada para o combate ao crime organizado transnacional), ajuda em desastres e execução de programas sociais.

Cabe ressaltar que a transformação militar, tanto nos países desenvolvidos quanto na América Latina, também possui uma dimensão internacional. Como foi visto, no caso dos primeiros, a eclosão de crises nas regiões periféricas do sistema internacional levou a uma busca pela criação de forças expedicionárias. Já na região latino-americana, essa dimensão internacional é encontrada tanto na incorporação das Forças Armadas a missões de paz sob comando da ONU, 
quanto nas relações com os EUA, especialmente no que tange à adesão da agenda de segurança hemisférica promovida pelas instituições e fóruns multilaterais, como a Organização dos Estados Americanos (OEA), a Junta Interamericana de Defesa (JID) e as Conferências de Ministros de Defesa das Américas (CMDA) (HERZ, 2002).

Durante a década de 1990, essa agenda de segurança promovida tanto pelas instituições norte -americanas, como o Departamento de Estado e o Departamento de Defesa - esse último principalmente por meio do Comando Sul (SOUTHCOM) -, quanto pelas hemisféricas, tem-sefundamentado sobretudo no conceito de segurança multidimensional, que tem sido incorporado pelas Forças Armadas dos países latino-americanos (SAINT-PIERRE, 2011). Em termos mais práticos, o foco dessa agenda tem sido o combate ao crime organizado (principalmente o narcotráfico), a imigração ilegal e os crimes ambientais, além da inclusão do combate a grupos considerados terroristas na região (HIRST, 2003; LOVEMAN, 2006). Os programas de assistência na área de segurança promovidos pelos EUA também têm se focadonas atividades de garantia da leie da ordem e no combate ao narcotráfico desde a década de 1990 (AYERBE, 2009).

Tendo em vista essa revisão teórica e histórica sobre transformação militar em geral e especificamente na América Latina, esse trabalho baseia-se na definição desse conceito como sendo um processo holístico cujo objetivo é o de gerar um novo perfil nas Forças Armadas de um país através de três principais mudanças: modernização tecnológica, reestruturação organizativa e renovação doutrinária. Com base nessa definição é que será analisado o recente processo de transformação militar na Colômbia que levou à formação de um perfil multimissão, como se verá.

\section{Transformação militar contrainsurgente (1998 -2010)}

A partir da década de 1990, o contexto de segurança da Colômbia foi determinado por três fatos: o fortalecimento estratégico das FARC e do ELN, a formação e o fortalecimento das Autodefesas Unidas da Colômbia (AUC) e a expansão dos negócios ligados ao narcotráfico. Desses, o que mais preocupava o Estado colombiano era a atuação das guerrilhas, sobretudo das Forças Armadas Revolucionárias da Colômbia (FARC) e do Exército de Libertação Nacional (ELN). Essas duas guerrilhas surgiram em 1964, formadas principalmente por uma base camponesa e, no caso das FARC, por combatentes das guerrilhas do Partido Liberal colombiano ${ }^{1}$. Apesar de suas ações desde esse período, foi só na década de 1990 que eles adquiriram maio relevância estratégica, dado o crescimento do número de seus combatentes, de suas unidades e de sua presença nacional (PÉCAUT, 2010).

Desse modo, entre 1995 e 1998, esse grupo havia infligido importantes golpes às Forças Públicas ${ }^{2}$ - tendo iniciado a transição de uma guerra de guerrilhas para uma guerra de movimentos, ou seja, de uma fase definida por ações de pequeno porte para outra em que eram utilizadas unidades maiores e em choque frontal com o Exército (MARTÍNEZ ÁVILA, 2008).É importante mencionar que outro ator importante no conflito armado colombiano foi as AUC, a principal união de organizações paramilitares do país e que contribuíram com as forças estatais no combate aos grupos guerrilheiros. Entretanto, é importante frisar que seus membros estiveram envolvidos em massacres de comunidades camponesas, líderes sociais e tráfico de drogas; mas dada a sua relevância como "retaguarda estratégica" do Exército, o combate a esse grupo não foi tão intenso quando comparado com o caso das guerrilhas (STOKES, 2005).

Nesse momento, a política de segurança dos EUA para a região direcionava-se para o combate ao narcotráfico e ao crime organizado, principalmente na região andina. Assim, o governo norte-americano pressionou a administração Pastrana para que aceitasse sua proposta do Plano Colômbia ${ }^{3}$ - caracterizada pela ênfase no combate militarizado ao

\footnotetext{
Esse partido utilizou grupos guerrilheiros para infligir derrotas sobre as forças do Partido Conservador durante o período de guerra civil vivido pelo país e que ficou conhecido como La Violencia, tendo sido caracterizado por enfrentamentos entre os dois partidos colombianos (VARGAS VELÁsQUEZ, 2012).

2 Na Colômbia, as Forças Públicas é a denominação que se dá ao conjunto das forças sob o comando do Ministério da Defesa, ou seja, as três Forças Armadas e a Polícia Nacional.

3 Inicialmente, o Plano Colômbia foi proposto pelo governo de Andrés Pastrana como um pacote de ajuda ao desenvolvimento socioeconômico da Colômbia, para o qual a comunidade internacional contribuiria com aportes financeiros (ROJAS, 2014).
} 
narcotráfico, contando com recursos financeiros e tecnológicos, além de assistência técnica e doutrinária para essas missões. Entretanto, a partir de 2003, com o governo Bush (2001-2009) nos EUA e Uribe (2002-2010) na Colômbia, o foco do programa passa a ser voltado também para of fortalecimento das Forças Armadas no combate aos grupos guerrilheiros, ainda que a maior parte dos recursos continuassem a ser destinados para o combate ao narcotráfico. Essa mudança se deu em grande parte pelo engajamento estadunidense na chamada "guerra ao terror" a partir dos atentados de 11 de setembro de 2001 (ROJAS, 2014).

Assim, nesse contexto de ameaças dos grupos guerrilheiros ao Estado colombiano, a administração de Andrés Pastrana empreendeu um processo de transformação militar entre $1998^{4}$ e 2010 que foi largamente apoiado pelos dirigentes políticos dos EUA. Apesar das variações tanto das decisões tomadas pelos governantes colombianos quanto do tipo de auxílio oferecido pelos EUA, o foco desse processo foi o combate aos grupos guerrilheiros e, em menor medida, às AUC. Foram importadas aeronaves, principalmente helicópteros, com a finalidade de transportar tropas do Exército para os teatros de operação e de oferecer apoio aéreo a proximado às forças terrestres; além disso, o sistema de inteligência militar foi incrementado com apoio do Comando Sul dos EUA, que forneceu radares baseados em terra para as Forças Armadas colombianas e ajudou na criação do Centro de Inteligência Conjunta. Também verificou-se um aumento no número de efetivos das Forças Armadas, passando de 154.878 para 276.296 entre 1998 e 2010 (VARGAS VELÁSQUEZ,2012; COLOMBIA, 2017).

Em termos organizacionais, as Forças Armadas colombianas passaram por um processo de re estruturação tanto no nível estratégico, quanto no operacional. No que tange ao primeiro caso, a estrutura de comando e controle do Estado Maior foi reorganizada a partir de 2003 com base na doutrina da integração entre as forças. Desse modo, foram criados cinco Comandos Conjuntos, cada um responsável por uma área do país. Já no nível operacional, foram criadas e fortalecidas novas unidades, geralmente com números maiores de efetivos e com integração entre as três forças, como foi o caso da Força de Emprego Rápido e das forças-tarefas conjuntas. Também foram criadas unidades de combate ao narcotráfico, como a Força-Tarefa Conjunta do Sul e a Brigada Antinarcóticos, ambas contando com assessoria norte americana (VARGAS VELÁSQUEZ, 2012). Por fim, esse processo contou com uma renovação doutrinária para o combate contrainsurgente. Foram incorporados os modelos de ação conjunta e de integração entre as forças, o que possibilitou maior êxito nas ações contra os grupos armados, bem como a doutrina de forças especiais, com apoio técnico de unidades do Exército dos EUA, que ajudaram a criar dois batalhões de forças especiais (PAGAN; MOYAR; GRIECO, 2014).

A partir de 2007, na segunda administração Uribe, com o enfraquecimento estratégico das FARC e do ELN, o Estado colombiano passou por um processo de mudança doutrinária, com a adoção da Ação Integral como eixo norteador das Forças Armadas para trabalharem em coordenação com outras instituições estatais nas áreas antes controladas pelos grupos armados. É importante mencionar que a doutrina de Ação Integral foi desenvolvida pela OTAN na década de 1990 para lidar com a situação de construção do pós-conflito em países saídos de confrontos armados internos, através de programas socioeconômicos voltados para o desenvolvimento das áreas afetadas pelo conflito (CASTILLO CASTAÑEDA; NIÑO GONZÁLEZ, 2015). Essa nova fase da transformação militar foi concretizada com a criação do Plano de Consolidação e contou com apoio financeiro e técnico do Comando Sul e da Agência dos EUA para o Desenvolvimento Internacional (USAID, na sigla em inglês). Esse seria o modelo doutrinário que passaria a ganhar cada vez mais relevância no processo de transformação seguinte (ROJAS, 2014).

Portanto, entre 1998 e 2010, as Forças Armadas da Colômbia passaram por um processo de transformação caracterizado, principalmente, por três resultados: modernização de seus armamentos e demais equipamentos militares; maior interoperabilidade entre as três forças, o que garantiu um aumento da mobilidade das forças terres tres pelo território nacional e uma renovação doutrinária para a atividade contrainsurgente.Por sua vez, esse processo esteveligado,

\footnotetext{
4 Apesar de o Plano Colômbia ter se iniciado em 2000, a assistência militar estadunidense para o combate ao narcotráfico já havia se iniciado antes, desde meados da década de 1980 e sobretudo na de 1990 (LOVEMAN, 2006).
} 
por um lado, à evolução da dinâmica do conflito armado interno, com o aumento da atividade guerrilheira durante a década de 1990 e início de 2000 e o fortalecimento estratégico pelo qual as FARC passaram e, por outro, à política de segurança dos EUA para a América Latina e, especificamente, para o país andino, que resultou na criação do Plano Colômbia, a fim de contribuir com os esforços de contrainsurgência das Forças Armadas. Entretanto, como se verá, as tendências identificadas no final desse período - ou seja, ênfase cada vez maior na doutrina de Ação Integral e no apoio das Forças Armadas a projetos de desenvolvimento socioeconômico em apoio a outras instituições civis - serão cada vez mais observadas no período seguinte.

\section{Transformação militar no pós-conflito}

Na década de 2010, um novo cenário de segurança na Colômbia passou a determinar o novo perfil que as Forças Armadas do país deveriam ter; por outrolado, as mudanças nas relações com os EUA também foram um importante fator na projeção internacional do país. Primeiramente, cabe mencionar que as FARC, após grande enfraquecimento estratégico, iniciaram diálogos de paz com o governo, que resultaram na assinatura dos Acordos de Havana em 2016. Essefato marcou a desmobilização da principal guerrilha do país após mais de cinquenta anos de conflito armado. Por outro lado, o ELN (a segunda organização guerrilheira remanescente e com alguma capacidade de ação armada) iniciou um processo semelhante em 2017. Entretanto, esse grupo armado tem continuado a realizar confrontos com as forças estatais, o que resultou nas dificuldades ainda existentes para a continuação das negociações entre a guerrilha e o Governo Nacional ${ }^{5}$.

Além desses acontecimentos, o atual cenário de segurança do país é marcado pela consolidação de dois atores armados que têm gerado instabilidade para as estruturas estatais. Em primeirolugar, após a desmobilização do grosso das FARC em 2017, verificou-se a atuação de dissidências da guerrilha, ou seja, unidades que não se sujeitaram aos Acordos de Havana. Por outro lado, tem sido observado um crescimento e fortalecimento das bandas criminais (BACRIM) em determinadas regiões urbanas e rurais do território colombiano. Dentre elas, destaca-se o chamado Clan del Golfo, a principal organização do país e atuante principalmente na região de Urabá, no departamento de Antioquia. Esses grupos têm atuado com uma estrutura herdada dos antigos grupos paramilitares, em termos de forma de organização (com utilização de pelotões de combatentes), domínio sobre rotas de narcotráfico e de aquisição de armamentos - e equipamentos de comunicação sofisticados - e de modo de atuação, ou seja, por meio do assassinato a líderes sociais e enfrentamento às forças policiais. Desse modo, apesar de sua desmobilização a partir de 2006, as AUC acabaram por influenciar no crescimento desses grupos rmados (MASSÉ, 2015; ÁLVAREZ VANEGAS et al., 2017).

\section{Primeira fase (2011-2015): declínio do perfil contrainsurgente}

Tendo em vista as mudanças no contexto securitário e a necessidade de revisar a estrutura criada no processo de transformação no período anterior, a partir de 2011, o Comando do Exército iniciou um processo de reorganização estrutural e de mudança de seu plano de guerra, com a finalidade de impor uma derrota final às FARC. Esse processo foi guiado principalmente pela Política Integral de Segurança e Defesa para a Prosperidade, que estab eleceu os eixos gerais da atuação das Forças Armadas no primeiro governo de Juan Manuel Santos (2010 -2014). Segundo esse documento, o cenário de que deveriam partir as tomadas de decisões do governo colombiano era o de enfraquecimento das guerrilhas e o crescimento das BACRIM. Dentre os objetivos estratégicos propostos por esse documento, constavam: combate ao narcotráfico, desarticulação das organizações criminosas e aumento da cooperação em segurança com outros Estados,

\footnotetext{
5 Atualmente, essa dificuldade também se deve à eleição de Iván Duque para a presidência do país em 2018, uma vez que este possui vínculos com os setores políticos mais conservadores, que apoiaram a não assinatura do Acordo de Havana. Dentre eles, Duque tem estabelecido fortes ligações com Álvaro Uribe e com Marta Lucía Ramírez (sua atual vice-presidente).
} 
principalmente no combate ao crime organizado transnacional. Com esse discurso, ogoverno Santos passava a dar maior ênfase ao conceito de segurança multidimensional ${ }^{6}$ (COLOMBIA, 2015).

Em termos quantitativos, observou-se um aumento no valor absoluto dos gastos em defesa e segurança, passando-se de US $\$ 8,4$ bilhões para US\$9,6 bilhões; entretanto, em termos de porcentagem do PIB, houve diminuição do orçamento, variando de 3,6\% para 3,3\% (SIPRI, 2020a; COLOMBIA, 2019). Por outro lado, verificou -se crescimento no número de efetivos das Forças Armadas entre 2011 e 2013, de 283.773 para 288.245; entretanto, a partir de 2014, esses números começam a cair, chegando a 247.290 em 2016 (COLOMBIA, 2017a). No referente às aquisições de equipamentos de defesa, observou-se maior diversificação, inclusive com a compra de armamentos voltados para defesa convencional, como veículos blindados, mísseis e embarcações; apesar disso, continuou-se a comprar aeronaves, sobretudo helicópteros, para uso no combate ao narcotráfico e aos grupos armados internos (SIPRI, 2020b).

Contudo, a transformação militar das Forças Armadas da Colômbia começou a dar-se principalmente nos aspectos organizacionais e doutrinários e sobretudo no Exército - onde foi iniciado esse processo. No início, essas mudanças focavam na reestruturação do sistema de comando e controle e no Estado-Maior da força e uma renovaçãoda estratégia de confronto com as FARC. Com isso, em 2011, foi criado o Comitê de Revisão Estratégica e Inovação (CREI), iniciativa conjunta entre oficiais do Exército e da Polícia, sob a supervisão do Ministério da Defesa e do Comando Geral das Forças Militares; por meio dele, foi estabelecido o plano de campanha Espada de Honor e o plano de guerra de mesmo nome (COLOMBIA, 2013).

Em 2013, foi constituído o Comitê Estratégico de Desenho do Exército do Futuro (CEDEF), cujo objetivo era criar um modelo de força terrestre denominado pelos oficiais colombianos "exército do futuro", executando políticas de nível estratégico e em alinhamento com as áreas de missão do setor Defesa. Por m eio desse comitê, o Comando do Exército começou a redesenhar a força, reestruturando-a e mudando seu emprego, o que acabou por definir um novo perfil de força, mais voltado para o combate às ameaças chamadas "multidimensionais". Também é importante ressalt ar que tanto o governo norte-americano quanto a OTAN estiveram relacionados com o planejamento da transformação do Exército colombiano por meio da presença de técnicos do Exército dos EUA, do Comando Sul e da organização militar nas atividades do CEDEF (CIRO GÓMEZ; CORREA HENAO, 2014).

Em termos de reestruturação organizacional, esta passou a ser executada a partir de 2015, seguindo as diretrizes estabelecidas pelo CREI 5, que envolveu oficiais das três forças, da Polícia Nacional e do Comando Sul dos EUA. Com a evolução do cenário de segurança da Colômbia, foram criados planos de transformação para as três instituições militares, começando pela reorganização do Estado-Maior do Exército, tendo como base os padrões da OTAN e do Exército estadunidense, dividindo-o em duas grandes áreas funcionais: gerador de força (relacionado ao planejamento e apoio às tropas) e gerador de combate (ligado ao emprego estratégico e à condução operacional). O Estado-Maior também foi dividido em três Chefaturas: Planejamento e Políticas, Gerador de Força e de Operações. Além disso, foram criados comandos assessores (COLOMBIA, 2016a).

No nível operacional, continuou-se a criar unidades para combater as FARC, seguindo a linha de ação traçada pelo plano Espada de Honor. Foram formadas nove forças de tarefa conjunta, somando um total de 12 distribuídas pelo território nacional. Também foram criadas e fortalecidas unidades especializadas em missões subsidiárias, como a Brigada contra Mineração Ilegal, uma Brigada de Desminagem Humanitária, a Brigada Especial de Engenheiros Militares, a Brigada de Construções e os Batalhões Especiais Energéticos e Viais (COLOMBIA, 2016a).

No caso da Marinha, o processo de transformação foi desenhado tendo cinco eixos estratégicos: Defesa Nacional, Segurança Marítima e Fluvial Integral, Apoio ao Desenvolvimento Marítimo e Fluvial, Segurança Ambiental, Marítima e Fluvial e Projeção Internacional.Assim, ficou estabelecido que a linha de atuação da Marinha no pós -conflito seria baseada

\footnotetext{
${ }^{6}$ Segundo Saint-Pierre (2011), esse termo está atrelado à agenda de segurança hemisférica proposta pelos EUA a partir do pós -Guerra Fria. Para o autor, tal conceito misturaria indiscriminadamente elementos de natureza diferente, de origens variadas, que requerem vários tipos derespostas e articuladas por diferentes agências estatais.
} 
numa abordagem de segurança multidimensional. Já a "projeção internacional" incluía atividades de cooperação triangular com os EUA, fortalecimento para o combate ao crime organizado e atuação em operações de paz e assistência humanitária. Por sua vez, a transformação da Força Aérea envolveu a criação de três comandos centrais: de Operações Aéreas, de Apoio à Força e de Pessoal (COLOMBIA, 2016a).

Embora a transformação das Forças Armadas colombianas tenha se consolidado mais na segunda fase, já na primeira é possível observar algumas mudanças no emprego e nas missões executadas, como demonstra o plano Espada de Honor. Com base nele, as Forças Armadas da Colômbia atuaram de modo conjunto e em coordenação com a Polícia Nacional a fim de realizar uma ofensiva simultânea contra as FARC e o ELN. Para cumprir essas missões foram criadas estruturas para auxiliar as Forças Armadas, como o Centro de Fusão de Inteligência Regional, para fortalecimento e coordenação da inteligência nas operações e a Companhia de Ação Integral, com a finalidade de melhorar as relações com a população das áreas antes dominadas pelas guerrilhas. As Forças Armadas também continuaram a ser empregadas em missões de apoio a projetos de desenvolvimento socioeconômico, seguindo o modelo da doutrina de Ação Integral, como foi o caso da participação no programa Fe en Colombia (COLOMBIA, 2015a).

Cabe ressaltar que, nesse processo, o governo colombiano buscou manter sua proximidade com as Forças Armadas norte-americanas e acercar-se da OTAN. Nesse sentido, os governos de Santos e Obama assinaram o Plano de Ação EUA-Colômbia para Cooperação em Segurança Regional em 2012, segundo o qual o Comando Sul auxiliaria com apoio técnico e financeiro o treinamento de unidades de forças de segurança de outros países por militares e policiais colombianos - sobretudo na América Centrale Caribe, áreas importantes para a política de segurança norte -americana na América Latina (ARRATIA SANDOVAL, 2016; TICKNER; MORALES, 2015).

Nesse sentido, entre 2013 e 2016, os técnicos colombianos treinaram mais de 11.000 efetivos de países como Panamá, Costa Rica, El Salvador, Honduras, Guatemala e República Dominicana (BEITTEL, 2017). Em termos de aproximação com a OTAN, o governo colombiano buscou adequar-se a seus padrões de procedimento na reestruturação organizacional do Exército e em normas e procedimentos das Forças Armadas, com a implementação do programa de Construção de Integridade e Redução de Corrupção e a assinatura do Acordo sobre Cooperação e Segurança de Informação, firmado em 2013 (COLOMBIA, 2016a).

Segunda fase (2016-2019): consolidação do perfilmultimissão

A assinatura dos Acordos de Paz de Havana em outubro de 2016 iniciou uma nova fase da transformação militar. Esse processo teve por base cinco documentos: no segundo mandato de Juan Manuel Santos, a Política de Defesa e Segurança Todos por um Novo País, o Plano Estratégico Militar 2030 (PEM 2030) e o Plano Estratégico do Setor Defesa e Segurança 2016-2018. No governo Duque, a Política de Segurança para a Legalidade, o Empreendimento e a Igualdade e o Plano Estratégico do Setor Defesa e Segurança 2018-2022.

De modo geral, os cinco documentos estabelecem os novos objetivos estratégicos e os tipos de missões para as Forças Armadas. Enfatizam o enfraquecimento das guerrilhas e a perspectiva de uma situação pós-conflito armado. Ao mesmo tempo falam do crescimento das BACRIM, das dissidências das FARC e das ações do ELN como principais fontes de ameaça à segurança nacional. Em termos de ação, é estabelecida uma gama de missões pa ra as Forças Armadas, a fim de atuarem de modo conjunto, em coordenação com a Polícia e sincronizados com agências estatais civis. Essas ações variam de defesa convencional a proteção ambiental, passando pelo combate ao crime organizado e pela gestão de risco e atuação em desastres. Além disso, o governo Santos também buscou estimular uma nova "projeção internacional" das Forças Armadas do país, o que incluiria principalmente as relações triangulares ${ }^{7}$ com os EUA, a aproximação com a OTAN, a

\footnotetext{
${ }^{7}$ Como ficará mais claro ao longo da seção, essas relações triangulares referem-se ao treinamento oferecido por oficiais colombianos a efetivos das forças de segurança principalmente de países da América Central e do Caribe com apoio de instituições norte-americanas, dentre as quais cabe destacar o Comando Sul.
} 
atuação em missões de paz da ONU. Portanto, em termos de discurso oficial, vê -se uma continuação em relação aos objetivos traçados na fase anterior (COLOMBIA 2015b;2015c; 2016b;2018; 2019).

Quanto aos dados quantitativos, apesar do aumento novalor absoluto do orçamento militar, passando de US $\$ 9,6$ bilhões para US\$10,7 bilhões entre 2016 e 2019, quando avaliado em porcentagem do PIB, observa -se uma estabilidade, passando de 3,1\% para 3,2\% (SIPRI, 2020a).Já em termos de efetivos, apesar da queda entre 2013 e 2017, passando-se de 285.008 para 245.429, a partir do ano seguinte, esse númerovoltou a subir, chegando a 293.200 (COLOMBIA, 2017a; IISS, 2020). No referente aos equipamentos militares adquiridos, apesar de se ter continuado a adquirir aeronaves, principalmente helicópteros, também prosseguiu-se com a tendência já iniciada na fase anterior de diversificação das compras, inclusive com importação de armamentos voltados para defesa convencional, como embarcações marítimas e mísseis antitanque ${ }^{8}$ (SIPRI, 2020b).

Também nesta fase o processo de transformação militar demonstrou ser mais proeminente nos aspectos organizacionais e doutrinários. Assim, continuou-se a reestruturação do Estado-Maior do Exército, com a criação de um comando ligado à doutrina de Ação Integral e projetos de desenvolvimento socioeconômico e com a criação de unidades baseadas na separaçãojá estabelecida na fase anterior entre um Estado-Maior gerador deforça e outro gerador de combate. $\mathrm{Na}$ esfera operacional, foram desativadas as seis forças de tarefa conjunta que haviam sido criadas entre 2011 e 2013, sendo substituídas por Comandos Operativos de Estabilização e Consolidação, voltados à manutenção do controle estatal em áreas antes dominadas pelos grupos armados (PÉREZ, 2018).

Foi criada uma força de tarefa conjunta composta por 3.200 membros das Forças Armadas e da Polícia para combater o Clan del Golfo, a maior BACRIM do país, ao mesmo tempo em que foram ativados o Comando de Apoio a Operações Urbanas do Exército e um Batalhão de Forças Especiais Urbanas, para atuar em coordenação com a Polícia no combate ao crime organizado. Também cabe mencionar a criação dos Centros Estratégicos de Operações contra o Narcotráfico, responsáveis por empregar cerca de 15.000 efetivos na erradicação de cultivos ilícitos e 40.000 em programas de erradicação e interdição no resto do país (PELCASTRE, 2018). Portanto, tanto a nível estratégico, quanto operacional, as Forças Armadas da Colômbia - e sobretudo o Exército - concentraram-se em missões de combate a "ameaças multidimensionais", como o crime organizado transnacional.

Em termos de renovação doutrinária, a principal iniciativa veio do Exército, com a criação da doutrina Damasco em 2016. Esta estabelece as Operações Terrestres Unificadas (OTU) como principal con ceito operacional da força, tendo como ideia central que esta "capture, retenha e explore a iniciativa, a qual se executa através da Ação Decisiva (ofensivas, defensivas, de estabilidade e de apoio da defesa à autoridade civil, ADAC), com o fim de criar as condições para uma resolução favorável do conflito" (COLOMBIA, 2016b, p. IX). Esse conceito também ressalta a necessidade de sincronização entre as Forças Armadas (missões conjuntas), com instituições estatais civis (missões coordenadas ou interagências) e com forças multinacionais. Cabe ressaltar que esse conceito foi elaborado pelo Exército dos EUA, constando no Army Doctrine Publication 3-0, Unified Land Operation, de 2011, tendo sido posteriormente adotado pelo Exército colombiano. Desse modo, a utilização de um conceito norte-americano também serve a um dos objetivos da nova doutrina, qual seja de alinhar seus procedimentos institucionais com os dos EUA e da OTAN (COLOMBIA, 2016b; ROJAS GUEVARA, 2017).

Essa nova doutrina também enfatiza o conceito de "força multimissão", entendida como capaz de adaptar-se a cenários distintos em teatros de operações diferentes. Assim, tanto o Exército quanto as demais forças já não teriam um caráter predominantementevoltado para o combate a grupos armados internos - como ocorreu na década passada -, mas sim para um lequevariado de missões, que abrangeriam desde aquelas ligadas à defesa convencional até o auxílio de gestão de risco e de desastres - em coordenação com agências civis -, passando pelo emprego contra estruturas ligadas ao crime organizado e na proteção do meio-ambiente (CIRO GÓMEZ; CORREA HENAO, 2014; ROJAS GUEVARA, 2017).

\footnotetext{
${ }^{8}$ Quanto a esse foco na defesa convencional, é importante lembrar que a segunda metade da década de 2010 foi marcada por tensões nas relações com a Venezuela (IISS, 2020).
} 
Essa mudança de perfil de força tem sido demonstrada na execução do Plano Estratégico Militar de Estabilização e Consolidação Victoria, executado a partir de 2017, em substituição ao Espada de honor como plano estratégico e de campanha do Comando Geral das Forças Militares. Ao invés de ser voltado predominantemente para o combate às guerrilhas, como o antecessor, seu foco recai nas outras ameaças à segurança nacional, principalmente nas regiões que antes estavam sob domínio das guerrilhas. Nesse sentido, é entendido como um plano direcionado para o pós -conflito armado. Sua execução baseia-se no conceito de OTU e na ação conjunta entre as três Forças Armadas, na coordenação com a Polícia e na sincronização com as agências estatais civis - sendo esses os principais componentes do conceito de ação unificada do Estado (COLOMBIA, 2017b).

Sua implementação concentra-se em três eixos: controle institucional do território, por meio da garantia de segurança às populações residentes em áreas antes sob controle das FARC; fortalecimento institucional, com estabelecimento de outras instituições civis e, por fim, cooperação e desenvolvimento, ou seja, utilização das Forças Armadas em projetos de desenvolvimento socioeconômico, em missões humanitárias, de proteção ambiental e cooperação internacional, direcionadas pela doutrina de Ação Integral (COLOMBIA, 2017b). Nesse sentido, o plano Victoria representa a consolidação da doutrina de Ação Integral como principal eixo de atuação das Forças Armadas, ao mesmo tempo em que o conceito de força multimissãoé usado para descrever o novo perfil das Forças Armadas da Colômbia.

Como resultado da revisão do plano Victoria, em 2018, foi lançado o plano Victoria Plus, voltado para combater principalmente os grupos ligados ao crime organizado - as BACRIM e as dissidências das FARC - e o ELN. Tendo como marco esse plano, tem sido elaborados alguns esforços operacionais para cumprir esses objetivos estratégicos: Operação Agamenón II, destinada a enfraquecer o Clan del Golfo e que, pela incapacidade das forças policiais em conseguirem lidar com essa BACRIM, foi necessária a atuação coordenada com as Forças Armadas; Operação Relámpago Rojo, cujo objetivo é combater as estruturas do ELN onde sua presença é maior; também tem sido realizada a operação Escudo Democrático, executada por meio de uma coordenação entre Forças Armadas (cerca de 2.300 efetivos) e a Polícia para a proteção de áreas urbanas (JIMÉNEZ MEJÍA, 2019).

Por fim, é importante considerar que a busca por uma projeção internacional como parceiro dos EUA e da OTAN continuou nessa fase, não apenas com a continuação de iniciativas anteriores, como o Plano de Ação EUA -Colômbia, mas também através da criação de novas iniciativas. Desse modo, em 2017, a Colômbia assinou um acordo com a OTAN em que era reconhecida como "parceiro global" da aliança. Com esta, tem-se desenvolvido também projetos de certificação de centro de desminagem humanitária do Exército colombiana e a coordenação em missões internacionais, que tem sido ajudada pela própria mudança nas doutrinas das três forças - elaboradas para terem maior integração com a organização, como no caso da Doutrina Damasco (COLOMBIA, 2016c).

Também tem-se buscado maior participação de tropas colombianas em missões comandadas pela ONU, com o governo colombiano tendo confirmado com a Secretaria Geral da organização a intenção de enviar até 5.000 efetivos em três anos. Ademais, vem sendo buscada uma maior aproximação com os países centro-americanos e caribenhos na área de segurança, com apoio norte-americano, como demonstrado com a participação na Conferência sobre Prosperidade e Segurança Centro-Americana - iniciativa conjunta entre EUA, México e os países da América Central (COLOMBIA, 2019).

\section{Considerações finais}

O presente trabalho buscou analisar a transformação das Forças Armadas colombianas que se deu a partir de 2011, limitando-se ao período que vai até 2019, a fim de compreender os principais sentidos desse processo. Foi usado o conceito de transformação militar elaborado por Sloan (2008) para analisar os casos dos países da OTAN e aplicado à América Latina por Villamizar (2003), Covarrubias (2004) e Alda (2019), entendido como um processo destinado a gerar capacidades para um novo papel para as Forças Armadas por meio de mudanças tecnológicas, organizacionais e 
doutrinárias. O trabalho partiu da hipótese de que esse processo estaria, por um lado, especializando as forças colombianas em missões subsidiárias e, por outro, dando continuidade ao processo de dependência militar com relação aos EUA, ainda que de modo diferente em relação ao período anterior.

Os resultados obtidos indicam que a partir de 2011, o Estado implementou grada tivamente um novo perfil nas Forças Armadas, denominado "multimissão". Nesse sentido, houve uma reestruturação organizacional na qual foram eliminadas algumas unidades criadas para o combate contrainsurgente e criadas outras destinadas a missões subsidiárias, como para ações contra o crime organizado e demais atividades ilícitas, bem como para apoio a projetos de desenvolvimento socioeconômico. Também foi realizada uma renovação doutrinária, com a criação da doutrina Damasco pelo Exército e com a adoção da doutrina de Ação Integral como um dos principais nortes para a atuação das três forças, como evidenciado tanto no plano Espada de Honor, quanto no Victoria.Já em termos de capacidades tecnológicas, não foi verificada uma mudança tão grande, o que poderá vir a mudar com a consolidação desse processo - e provavelmente devido à "nacionalização" de equipamentos adquiridos sob o marco do Plano Colômbia.

Dessa forma, o novo perfil apresentado pelas Forças Armadas colombianas tem sido marcadamente diferente em relação ao adotado durante a transformação anterior. Enquanto entre 1998 e 2010 foram desenvolvidas forças voltadas para a intensificação do combate contrainsurgente, por meio de uma modernização dos equipamentos militares, um aumento no número de efetivos, sobretudo aqueles que compunham a força terrestre e maior interoperabilidade entre as forças, tanto no nível estratégico quanto no operacional.Já o processolevado a cabo entre 2011 e 2019 (e ainda em vigor) tem sido caracterizado principalmente por um reestruturação organizacional com menor ênfase no combate contrainsurgente e por uma renovação doutrinária destinada tanto a uma maior gama de ações subsidiárias internas quanto a uma maior projeção internacional, por meio da utilização do know-how adquirido durante o primeiro período.

Por sua vez, esse novo processo de transformação militar tem objetivo a criação de uma força multimissão, com foco principalmente no apoio à implementação de projetos de desenvolvimento socioeconômico em regiões antes marcadas pelo conflito com as guerrilhas e no apoio ao combate ao crime organizado. Quanto a isso, é importante analisarse criticamente, uma vez que esse processo pode levar tanto a uma desprofissionalização das Forças Armadas, ao perpetuar seu papel análogo ao de corpos policiais ("policialização"), quanto a uma militarização da segurança pública (FERREYRA WACHHOLTZ; SAINT-PIERRE, 2019). Inclusive, essas têm sido as características predominantes em grande parte das Forças Armadas latino-americanas, que não correspondem à dicotomia comumente citada entre Defesa (ações de combate contra ameaças externas, sobretudo de caráter estatal) e Segurança (garantia da ordem interna contra grupos delinquentes ou outras ações de caráter interno) (SUCCIJUNIOR., 2020).

Por outro lado, tanto o processo de reestruturação organizacional, quanto de renovação doutrinária das Forças Armadas colombianas têm sido desenhados para uma projeção internacional do país que perpetue a dependência com relação aos EUA. Esta já não seria baseada fundamentalmente no aspecto tecnológico, como foi durante a vigência do Plano Colômbia, mas sim no doutrinário e técnico, buscando levar a expertise criada pelas relações com os EUA na década de 1990 e 2000 para os países da América Centrale do Caribe. É nesse sentido que Tickner e Morales (2015) têm afirmado essa relação tem sido caracterizada como uma "cooperação dependente associada", que continua a servir primariamente aos interesses norte-americanos, sendo os da Colômbia acoplados a eles. Também essa dependência tem sido evidenciada na maior aproximação com a OTAN, tanto em termos doutrinários, quanto procedimentais. É importante mencionar que esse tipo de "projeção internacional" do país também é significativo para a manutenção de certa entrada de recursos das instituições norte-americanas e da aliança militar. Assim, a hipótese inicial tem sido corroborada pelos resultados da pesquisa. 


\section{Referências}

ALDA MEJÍAS, Sonia. Fuerzas armadas entrenadas para la defensa exterior, apoyando la lucha contra el crimen organizado: ¿qué cambios se requieren? ¿adaptación, modernización o transformación?. In: SAMPÓ, Carolina; ALDA, Sonia. La transformación de las Fuerzas Armadas en América Latina ante el crimen organizado. Lima: Centro de Estudios Estratégicos, 2019 , p. 35 - 62.

ÁLVAREZ VANEGAS, Eduardo et al. Crimen organizado y saboteadores armados en tiempos de transición. Bogotá: Fundación Ideas Para La Paz, 2017.

ARRATIA SANDOVAL, Esteban. From "failed state" to exporter of security?: Colombia and the diplomacy of security. Austral: Brazilian Journal of Strategy \& International Relations, Porto Alegre,v. 5, n. 10, p.148 -172, 2016.

AYERBE, Luís. De Clinton a Obama : políticas dos Estados Unidos para a América Latina. São Paulo: Unesp, 2009.

BEITTEL, June. Colombia: Background and U.S. Relations. Washington, D.C.: Congress Research Service (CRS), 2017.

CASTILLO CASTAÑNDA, Alberto; NIÑNO GONZÁLEZ, César. La Doctrina de Acción Integral como política de seguridad en el posconflicto armado en Colombia. In: NIÑO, César Augusto (Comp.). Perspectivas y prospectivas de la seguridad en Colombia. Bogotá: Universidad Santo Tomás, 2015.p. 121-148.

CIRO GÓMEZ, Andrés; CORREA HENAO, Magdalena. Transformación estructural del Ejército colombiano: Construcción de escenarios futuros. Revista Científica General José María Córdova, Bogotá, v. 12, n. 13, p.19-88, 2014

COLOMBIA. Memorias al Congreso: 2012-2013. Bogotá: Ministerio de Defesa Nacional, 2013.

COLOMBIA. Memorias al Congreso: 2014-2015. Bogotá: Ministerio de Defesa Nacional, 2015 a.

COLOMBIA. Política de Defensa y Seguridad Todos por un Nuevo País. Bogotá, $2015 b$.

COLOMBIA. Comando General de las Fuezas Militares. Plano Estratégico Militar 2030. Bogotá: Comando Geral das Forças Militares, 2015 c.

COLOMBIA. Memorias al Congreso:2015-2016. Bogotá: Ministerio de Defesa Nacional, 2016a.

COLOMBIA. Ministerio de Defensa Nacional. Plan Estratégico del Sector Defemsa y Seguridad 2016 -2018: Guía de Planeamiento Estratégico. Bogotá: Ministerio de Defesa Nacional, 2016b.

COLOMBIA. Ejército Nacional de Colombia. Doctrina Damasco. Bogotá: Exército Nacional da Colômbia, 2016c.

COLOMBIA. Información de Criminalidad, resultados operacionales, afectación de las propias tropas y pie de fuerza. Bogotá: Ministerio de Defensa Nacional, 2017a.

COLOMBIA. Memórias ao Congresso: 2016-2017. Bogotá: Ministerio de Defesa Nacional, 2017b.

COLOMBIA. Ministerio de Defensa Nacional. Plan Estratégico del Sector Defemsa y Seguridad 2018-2022: Guía de Planeamiento Estratégico. Bogotá: Ministerio de Defesa Nacional, 2018.

COLOMBIA. Memórias ao Congresso: 2018-2019. Bogotá: Ministerio de Defesa Nacional, 2019.

COVARRUBIAS, Jaime. New Threats and Defense Transformation: the case of Latin America. Low Intensity Conflict \& Law Enforcement, [s.1.], v. 12, n. 3, p. 144-155, mar. 2004

DANDEKER, Christopher. Building Flexible Forces for the 21st Century: key challenges for the contemporary armed services. In: CAFORIO, Giuseppe. Handbook of the Sociology of the Military. New York: Springer, 2006.p. 405-416.

HERZ, Monica. Política de segurança dos EUA para a América Latina após o final da Guerra Fria. Estudos Avançados, São Paulo, v. 46, n. 16, p.85-104,2002.

HIRST, Monica. Seguridad regional en las Américas. In: GRABENDORFF, Wolf. La seguridad regional en las Américas: Enfoques críticos y conceptos alternativos. Bogotá: Cerec, 2003.p. 25-80.

HUNTER, Wendy. State and Soldier in Latin America: Redefining the Military's Role in Argentina, Brazil and Chile. Washington, D.C: United States Institute Of Peace, 1996.

INTERNATIONAL INSTITUTE FOR STRATEGIC STUDIES (IISS). The Military Balance. Londres: IISS, 2020. 
JIMÉNEZ MEJÍA, Ricardo. Victoria Plus, hoja de ruta del Ejército 2018.2019. Disponível em: https://publicacionesejercito.mil.co/recurso_user/revista_ejercito/Revista_194/victoria-plus-hoja-de-ruta-del-ejercito-2018.html. Acesso em: 22 set. 2020.

KALDOR, Mary. New \& Old Wars: Organized violence in a global era. 3. ed. Malden: Polity Press, 2012.

LOVEMAN, Brian. U.S Security Policies in Latin America and the Andean Regional: 1990 -2006. In: LOVEMAN, Brian (Org.). Addicted to Failure: U.S. Security Policy in Latin America and the Andean Region. Lanham: Rowman \& Littlefield, 2006.p. 1-52.

MASSÉ, Frédéric. Transformaciones recientes y perspectivas de las "Bacrim". In: VARGAS, Alejo Velásquez; GARCÍA, Viviana Pinzón. Seguridad y defensa en la transición de la guerra a la paz reflexiones y perspectivas. Bogotá: Universidad Nacional de Colombia, 2015. p. 17-31.

MANIGART, Philippe. Restructuring of the Armed Forces. In: CAFORIO, Giuseppe (ed.). Handbook of the Sociology of the Military. New York: Springer, 2006.p. 324-343.

MARTÍNEZ ÁVILA, Ariel. FARC: Dinámica Reciente de la Guerra. Bogotá: Fundación Ideas Para La Paz, 2008.

MOSKOS, Charles C.; SEGAL, David R; WILLIAMS,John Allen. Armed Forces after the Cold War. In: MOSKOS, Charles C.; WILLIAMS, John Allen; SEGAL, David R. (Ed.). The Postmodern Military: Armed Forces after the Cold War. Nova Iorque: Oxford University Press, 2000.p.1-13.

PAGAN, Hector; MOYAR, Mark; GRIEGO, Will. Persistent Engagement in Colombia. Florida: JSOU Press, 2014.

PÉCAUT, D.; BENEDETTI, I. C. As FARC : uma guerrilha sem fins? São Paulo: PazE Terra, 2010.

PELCASTRE,Julieta. Colombia Activates Strategic Operational Centers Against Narcotrafficking | Diálogo Americas. 2018. Disponível em: https://dialogo-americas.com/articles/colombia-activates-strategic-operational-centers-against-narcotrafficking/.

PÉREZ, William. Transformación del Ejército: Garantía de futuro institucional. Revista Experticia Militar, Bogotá, v. 1, n. 1, p.12-19, 2018.

PION-BERLIN, David. Military missions in democratic Latin America. California: Palgrave Macmillan, 2016.

ROJAS, Diana. El Plan Colombia: la intervención de Estados Unidos en el conflicto armado colombiano (1998 - 2012). Bogotá: IEPRI, 2014.

ROJAS GUEVARA, Pedro. Doctrina Damasco: eje articulador de la segunda gran reforma del Ejército Nacional de Colombia. Revista Científica General José María Córdova, v. 15, n. 19, p.95-119, 2017. Escuela Militar de Cadetes José María Córdova.

SAINT-PIERRE, Héctor. “Defesa” ou "segurança”?: reflexões em torno de conceitos e ideologias. Contexto Internacional, [s. 1.], v. 33, n. 2, p. 407-433,2011. Acesso em: 18 set. 2020.

FERREYRA WACHHOLTZ, Matías; SAINT-PIERRE, Héctor. What is the purpose of "multipurpose forces"? The case of the Colombian armed forces in the "post-agreement." Revista Brasileira de Estudos de Defesa (RBED), [s. 1.], v. 6, n. 1, p. $27-49,2019$.

STOCKHOLM INTERNATIONAL PEACE RESEARCH INSTITUTE (SIPRI). Military expenditure by country, in constant (2018). Solna: Stockholm International Peace Research Institute,2020a. Disponível em: https://bit.ly/2xBeLDB. Acesso em: 22 out. 2020.

STOCKHOLM INTERNATIONAL PEACE RESEARCH INSTITUTE (SIPRI). Transfers of major weapons: Deals with deliveries or orders made for 1998 to 2017. Solna: Stockholm International Peace Research Institute, 2020b.

STOKES, Doug. America's other war: Terrorizing Colombia. Londres: Zed Books, 2004.

SLOAN, Elinor. Military transformation and modern warfare: A reference handbook. Westport: Praeger Security International, 2008.

SUCCI JUNIOR, D. P. O doméstico e o internacional como discurso normativo: a legitimação do uso da força. Carta Internacional, [S. l.], v. 15, n. 1, 2020.

TICKNER, Arlene; MORALES, Mateo. Cooperación dependiente asociada: Relaciones estratégicas asimétricas entre Colombia y Estad os Unidos. Colombia Internacional, Bogotá, v. 1, n. 85, p.171-205, 2015.

TERRIFF, Terry; FARRELL, Theo. The Sources of Military Change. In: TERRIFF, Terry; FARRELL, Theo. The sources of miliary change: culture, politics, technology. Culture, politics, technology. New York: Lynne Rienner Publishers, 2001.p. 3-20. 
VARGAS VELÁSQUEZ, Alejo. Las Fuerzas Armadas en el Conflicto Colombiano: Antecedentes y Perspectivas. Medellín: La Carreta Política, 2012.

VILLAMIZAR, Andrés. Fuerzas Militares para la Guerra: La Agenda Pendiente de la Reforma Militar. Bogotá: Fundación Seguridad y Democracia, 2003.

\begin{tabular}{ll}
\hline Funções de colaboração exercidas & \\
\hline João Estevam dos Santos Filho: & $\begin{array}{l}\text { Conceituação; Metodologia; Curadoria de dados; Administração do projeto; Visualização; Análise form al; Obtenção de } \\
\text { financiamento; Investigação; Escrita (primeira redação); Escrita (revisão e edição); }\end{array}$ \\
& $\begin{array}{l}\text { Conceituação; Metodologia; Validação; Administração do projeto; Visualização; Análise formal; Recursos; Investigação; } \\
\text { Alexander Arciniegas Carreño: }\end{array}$ \\
\hline
\end{tabular}

Informaçóes fornecidas pelos(as) autores(as) de acordo com a Taxonomia de Funçôes de Colaborador (CRediT) 